\title{
COMMENT
}

\section{Global Pediatric Research Investigator: Mohammod Jobayer Chisti}

\author{
Mohammod Jobayer Chisti ${ }^{1}$
}

Pediatric Research (2020) 88:689; https://doi.org/10.1038/s41390-020-1087-z

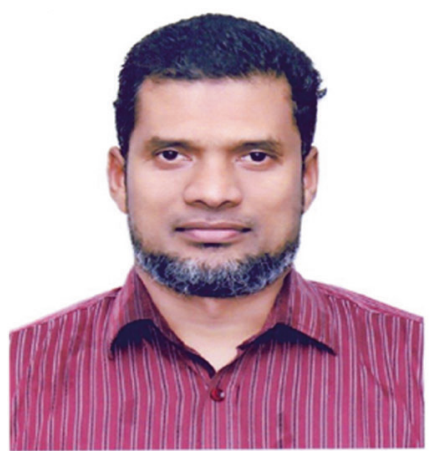

I was born and raised in 13, a village in the northeast of Bangladesh, where I studied for 7 years. I then accompanied my father to the capital city of Dhaka to complete my secondary and higher secondary education. I then graduated from a public medical college and began a 1 year internship in the town of Sylhet.

On my first night as an intern on the pediatric ward, I was terrified; sadly, I witnessed the death of three children from the simple diagnosis of pneumonia. Despite receiving all available treatment in the tertiary hospital at that time, these children did not survive. I knew we had to do better. This experience was what first sparked my interest in pediatrics and eventually led me down the path of studying respiratory and critical care medicine.

I then acquired a position as a Clinical Fellow at the International Centre for Diarrhoeal Disease Research Bangladesh (icddr,b). The relentless dedication of icddr,b physicians spearheaded by Dr. M.A. Salam and Prof. Tahmeed Ahmed inspired me. I fell in love with icddr,b and was thrilled to acquire a position for a Masters in Pediatric Medicine and then pursed a Ph.D. in Pediatric Respiratory Medicine at the University of Melbourne in Australia. Under the guidance of Prof. Trevor Duke, I completed an important project evaluating the impact of locally made lowcost innovative bubble continuous positive airway pressure (bCPAP) as compared to World Health Organization recommended low flow oxygen therapy and demonstrated a $75 \%$ reduction in mortality. Given this dramatic finding, bCPAP soon became standard of care in the Intensive Care Unit (ICU) at icddr,b with great impact. Implementation of bCPAP is already underway in Bangladesh and Ethiopia with the inspirational leadership of Prof. John Clemens, Executive Director of icddr,b. Recent crisis of COVID 19 ignited me to find bilateral global collaborations, such as those with Dr. Kache from Stanford School of Medicine in USA, and found to be beneficial.

I now have the privilege of being a Senior Scientist and the Clinical Lead of the ICU at icddr,b. I am grateful to my parents for their adoring encouragement and to my wife and three sons for their love and support as I spend many hours attending to my clinical and research responsibilities.

As for advice to young clinician researchers: be compassionate, expect to research to fail many times before finding success, maintain effective collaboration, and use your fears as motivation. I am grateful to all those who have encouraged, supported, educated, and collaborated with me over the years.

${ }^{1}$ Nutrition and Clinical Services Division, International Centre for Diarrhoeal Disease Research, Bangladesh, Dhaka 1212, Bangladesh

Correspondence: Mohammod Jobayer Chisti (chisti@icddrb.org)

Received: 11 July 2020 Accepted: 13 July 2020

Published online: 25 July 2020 